\title{
O Papel da ONU e do Banco Mundial na Consolidação do Campo Internacional de Desenvolvimento*
}

Fernanda Cimini Salles**

\section{Introdução}

final da Segunda Guerra Mundial é marcado por um grande esforço das nações desenvolvidas para a consolidação de arranjos institucionais que fossem capazes de promover a paz mundial. Naquele momento, não havia clareza das formas efetivas para se alcançar tal objetivo, mas algumas preocupações norteavam essa agenda. Primeiramente, a necessidade de reconstrução da Europa, destruída pela Grande Guerra, diante do temor de que a fragilidade social e econômica daquelas sociedades favorecesse a emergência de lideranças autoritárias e predispostas ao conflito. Em segundo lugar, a desconfiança de que a pobreza e as baixas condições econômicas e sociais nos países periféricos os conduzissem para o alinhamento

* Artigo recebido em 26 de dezembro de 2014 e aprovado para publicação em 18 de fevereiro de 2015 .

** Doutora em Sociologia pela Universidade Federal do Rio de Janeiro (UFRJ), Rio de Janeiro, RJ, Brasil. E-mail: fernandacimini@gmail.com. 
com a União Soviética, acirrando as rivalidades entre os blocos capitalista e socialista.

É nesse contexto de preocupações com a estabilidade econômica e com a segurança internacional - e sob os auspícios da política externa estadunidense - que são criados os primeiros instrumentos para operacionalização das políticas de desenvolvimento no âmbito das Nações Unidas. Os Artigos de Acordo do chamado "Sistema Bretton Woods" previam a criação do Fundo Monetário Internacional (FMI) e do Banco Internacional para Reconstrução e Desenvolvimento (BIRD), que, juntos, tinham como objetivo garantir a estabilidade do sistema financeiro internacional e estimular o crescimento econômico. Se, por um lado, o FMI dispunha de recursos financeiros e poderes de monitoramento para controlar o movimento de capitais internacionais e penalizar os países que adotavam medidas financeiras irresponsáveis, por outro lado, o BIRD funcionaria como uma agência internacional de empréstimos, disponibilizando capital para investimentos produtivos.

Neste momento de emergência do discurso do desenvolvimento na política internacional, observava-se um processo complexo de criação e consolidação de instituições, em que os países dominantes delegavam gradualmente às organizações internacionais recém-criadas a tarefa de promoção do desenvolvimento. Naquele momento, não estava claro qual seria o papel dessas novas organizações, qual o tipo de ações elas desempenhariam, como elas poderiam intervir nas políticas de seus Estados-membros, muito menos que desenvolvimento era esse que elas deveriam promover.

Contudo, vinte anos após a Conferência de Bretton Woods, esses organismos adquiriram condições empíricas (capital econômico, social e científico) para realizar atividades de apoio e fomento técnico e financeiro visando a promoção do desenvolvimento em escala internacional. Ao mesmo tempo, essas atividades ganharam apoio dos 
O Papel da ONU e do Banco Mundial na Consolidação do Campo Internacional...

países desenvolvidos que viam na agenda de desenvolvimento uma estratégia para lidar com as desigualdades econômicas em escala internacional. Assim, o campo de desenvolvimento internacional, que toma como referência os padrões estabelecidos em Bretton Woods, gradualmente se consolidou como um arranjo institucional coletivo, passando a lidar com questões mais complexas.

O ponto crítico deste momento - que nos permite, inclusive, falar na consolidação do campo - será o reconhecimento, por parte do Banco Mundial e da ONU, de que existiam diferentes caminhos possíveis para o desenvolvimento e que a escolha do melhor caminho estava nas disputas e jogos travados pelos próprios agentes do campo. A Comissão Pearson, realizada em 1969, teria apontado alguns elementos desse jogo, evidenciando que não bastava promover políticas de ajuda para o desenvolvimento, mas que essas políticas deveriam ser eficientes e, portanto, seguir certos critérios estabelecidos por aqueles engajados nessas práticas. A partir de então, outras movimentações políticas foram se somando a esse jogo, tornando ainda mais complexa a disputa entre ONU e Banco Mundial, a ponto de ser possível perceber a emergência de dois projetos políticos distintos e conflitantes para a formação de uma doxa do campo.

Assim, este artigo tem por objetivo evidenciar os elementos em disputa na constituição do campo de desenvolvimento e também chamar atenção para como a constituição desse arranjo institucional contribuiu para redimensionar a desigualdade em escala internacional.

\section{As Condições para Consolidação do Campo de Desenvolvimento a partir da Comissão Pearson}

Tornar eficiente a ajuda não é simplesmente uma questão de procedimento e técnicas. Mais 
importantes ainda são a organização global e a definição de objetivos. À medida que o sistema de ajuda tem crescido, seus canais se têm multiplicado e embaraçado. A não ser que a mecânica adquira maior coerência, a ajuda não poderá ser aproveitada ao máximo (PEARSON, 1969a, p. 232).

A década de 1960 representou um marco na história da cooperação internacional para o desenvolvimento, pois se, por um lado, foi considerada pelas Nações Unidas como a "década do desenvolvimento", por outro, foi nesse período que se iniciou a onda de reflexões que alteraria os rumos das políticas de desenvolvimento adotadas pelo Banco Mundial desde sua criação. Se até esse momento as práticas dos organismos internacionais seguiam uma lógica mais ou menos consensual e estável, passados vinte anos de existência do arranjo multilateral para a promoção do desenvolvimento, essas práticas precisaram ser revistas e rearticuladas vis-à-vis os questionamentos $\mathrm{e}$ críticas oriundos dos países-membros - principalmente dos países do Terceiro Mundo -, acadêmicos e organismos não estatais.

A principal inquietação que desestabilizava a rotina dos organismos multilaterais era a desconfiança de que a estratégia adotada por eles não seria suficiente para promover o desenvolvimento dos países pobres, pois, a despeito dos bilhões de crédito disponibilizados pelo Banco Mundial e governos doadores e das assistências técnicas providas pela ONU, os países beneficiados pela cooperação continuavam em situações de miséria e atraso econômico. Diante disso,

[...] em 27 de outubro de 1967, em um ambiente de crescente preocupação pelo futuro da cooperação internacional para o desenvolvimento econômico, o então presidente do Banco Mundial, Sr. George Woods, sugeriu que se convocasse uma assembleia de alto nível, em que um grupo internacional de prestígio e experiência se reunisse para estudar as conse- 
O Papel da ONU e do Banco Mundial na

Consolidação do Campo Internacional...

quências de vinte anos de ajuda ao desenvolvimento, avaliar os resultados, explicar os erros e propor políticas mais eficazes para o futuro. (PEARSON, 1969a, p. 9). ${ }^{2}$

A chamada "Comissão Pearson", liderada pelo ex-primeiro-ministro canadense e Prêmio Nobel da Paz Lester B. Pearson, reuniu, durante dois anos consecutivos, especialistas de sete países para a elaboração de um estudo que contemplasse uma análise "da história recente da cooperação internacional para o desenvolvimento, com vistas a formular conclusões e recomendações acerca da cooperação para as próximas décadas" (PEARSON, 1969a, p. 9). Após onze meses de estudos, a Comissão divulgou, em 1969, o Relatório Final com os principais resultados da análise. Na ocasião da divulgação do relatório, representantes dos países-membros do Banco Mundial tomaram conhecimento de uma série de dados sobre a cooperação internacional para o desenvolvimento ainda não conhecidos, possibilitando a visualização e a discussão de seus principais problemas e avanços.

Embora o relatório tenha sido encomendado pelo Banco Mundial, para a elaboração do estudo foi necessária uma constante interlocução entre os especialistas da equipe Pearson com funcionários e autoridades das Nações Unidas e outras organizações internacionais atuantes no campo do desenvolvimento, em especial o Comitê de Assistência ao Desenvolvimento (CAD), vinculado à Organização para Cooperação e Desenvolvimento Econômico (OCDE). ${ }^{3}$ No momento de elaboração desse relatório, já era possível ter uma visão mais clara do desenho institucional da ajuda para o desenvolvimento, de quais eram as organizações oficiais que atuavam especificamente com políticas de assistência internacional e também de quais eram os campos de ação possíveis em torno dessa temática. Aliás, um conceito que emerge nesse período para sinalizar esses elementos de definição do objeto da cooperação para o desenvolvimento é o da "ajuda oficial ao desenvolvimento". Por ajuda oficial ao desenvolvimento (OAD), entende-se: 


\section{Fernanda Cimini Salles}

[...] as doações e os empréstimos concedidos a países e territórios na Parte I da lista de destinatários beneficiados (países em desenvolvimento) do CAD (Comitê de Assistência ao Desenvolvimento), os quais: (a) sejam garantidos por um setor oficial; (b) tenham a promoção de desenvolvimento econômico e bem-estar como objetivos principais; (c) sejam realizados em termos financeiros concessionais (se um empréstimo tem um elemento de doação de pelo menos $25 \%$ ). Além de fluxos financeiros, a cooperação técnica é incluída na ajuda. Doações, empréstimos e créditos para propósitos militares são excluídos. (OCDE, [s.d.]).

Ao se delimitar aquilo que é considerado a prática oficial de desenvolvimento, delimitam-se também os agentes elegíveis para a sua atuação, pois ficam excluídos os fluxos financeiros e técnicos que não tenham algum caráter concessional, bem como os agentes não oficiais, como organizações não governamentais e agências não reconhecidas pela OCDE. Esse esforço de definição do objeto legítimo do desenvolvimento veio ao encontro da necessidade inerente a todo campo de criar uma lógica própria, um "todo integrado" (PEARSON, 1969b), autônomo em relação ao mundo social mais amplo. Ora, ao se definir o que era ajuda oficial para o desenvolvimento em contraposição a outros tipos de ajuda (como a militar), observa-se uma tomada de posição das organizações internacionais enquanto agentes para definição das regras do jogo e, principalmente, de um posicionamento em relação às dinâmicas próprias da política internacional.

Ao representarem um papel de destaque como intermediários nesse debate que existe entre os concessores e os usuários de ajuda, as organizações internacionais muito fazem para emprestar à assistência ao desenvolvimento o caráter de esforço realmente internacional, redu- 
O Papel da ONU e do Banco Mundial na

Consolidação do Campo Internacional...

zindo as nuances de caridade ou intervencionismo que às vezes azedaram o processo de ajuda no passado (PEARSON, 1969a, p. 238).

Nesse momento, a ajuda internacional oferecida pelos Estados Unidos já não era tão dominante: "desde então muitos outros países começaram a conceder financiamento bilateral ao desenvolvimento, e do lado multilateral pelo menos uma dúzia de instituições foi fundada" (PEARSON, 1969a, p. 232) para além das instituições de Bretton Woods e das agências especializadas das Nações Unidas. Mesmo com a proliferação de organizações multilaterais, o aumento do engajamento dos países desenvolvidos nas práticas de ajuda tornava ainda mais assimétrica a balança entre assistência para o desenvolvimento multilateral e bilateral, em que essa última se destacava. Assim, a criação do CAD representou um importante esforço no sentido de coordenar e mensurar os fluxos da ajuda de desenvolvimento para que ela não se desviasse dos termos "oficialmente" delimitados. Ao mesmo tempo, a ONU, por meio do Conselho Econômico e Social (na sigla em inglês, Ecosoc), passou a atuar ativamente na delimitação das atividades de suas agências especializadas e foram estabelecidos consórcios para coordenar programas de ajuda em cada um dos países em desenvolvimento.

Contudo, o Relatório Pearson veio criticar justamente a mecânica existente de coordenação da ajuda internacional para o desenvolvimento, questionando sua incapacidade de equilibrar a ajuda bilateral e multilateral em torno de uma mesma estratégia: "Há considerável incerteza quanto ao papel das organizações internacionais, e há ainda a questão mais ampla de como idealizar uma estratégia internacional para o desenvolvimento que leve em consideração não só os problemas de ajuda, como também os de comércio, movimento de capitais e de tecnologia" (PEARSON, 1969a, p. 232). Uma das questões problemáticas colocadas pelo Relatório Pearson que afetava os interesses diretos das organizações internacionais era a presença ainda ma- 
ciça da ajuda bilateral concedida pelos países desenvolvidos. ${ }^{4} \mathrm{O}$ receio da permanência desse tipo de ajuda era que, na relação bilateral doador/beneficiário, os agentes do campo perderiam o controle sobre a operacionalização do desenvolvimento, tendo em vista que outros interesses poderiam desviar o foco dos recursos transferidos, e as políticas estariam "governadas por considerações diplomáticas ou comerciais" (PEARSON, 1969a, p. 233) concorrentes à lógica do desenvolvimento. É interessante observar que países desenvolvidos com poucas relações históricas com os países menos desenvolvidos, como os escandinavos, já estavam dispostos a canalizar maior parte da sua OAD por meio de canais multilaterais e advogavam por essa modalidade, ao passo que ex-metrópoles utilizavam majoritariamente as vias bilaterais (MARTINUSSEN; PEDERSEN, 2003).

Por outro lado, o relatório apontava uma incapacidade das próprias organizações multilaterais para atuar em setores importantes da cooperação para o desenvolvimento, tais como "planejamento familiar, desenvolvimento rural integrado, empresas industriais do setor público ou financiamento de projetos de pequena escala" (PEARSON, 1969a, p. 233) e ainda eram acusadas por estarem seguindo "filosofias errôneas de ajuda, ou duras demais, ou suaves demais; ou que são simplesmente mal administradas e cujos processos são lentos e dispendiosos" (PEARSON, 1969a, p. 233). Além disso, nos anos 1960, a demanda por participação dos países em desenvolvimento, não só como beneficiários, mas como tomadores de decisão nos arranjos multilaterais, ressoou com maior intensidade. Representantes desses países acreditavam que sua participação orientaria melhor as práticas e políticas desses organismos perante as especificidades particulares do desenvolvimento em cada país. ${ }^{5}$ Questões como agricultura, educação e indústria precisariam de uma maior atenção dos projetos de desenvolvimento bem como questões de natureza técnica como administração, formação de instituições, estudos de viabilidade e preparação de projetos (PEARSON,1969b). 


\section{O Papel da ONU e do Banco Mundial na}

Consolidação do Campo Internacional...

Em geral, todas as questões levantadas pelo Relatório se tratavam de críticas "propositivas" que tinham como objetivo a busca por soluções de problemas identificados na cooperação internacional, visando o próprio fortalecimento do arranjo multilateral por acreditar que esse arranjo seria o mais coerente com os objetivos do desenvolvimento internacional. Mas, para tanto, os recursos disponibilizados às organizações internacionais precisavam ser expandidos consideravelmente: "somente com recursos assim, muito aumentados, é que as agências internacionais de desenvolvimento poderão representar um papel significativo na compensação das distorções causadas pelos critérios bilaterais de distribuição" (PEARSON, 1969b, p. 238). Não por acaso, a primeira recomendação colocada pelo Relatório para fortalecer as organizações internacionais de desenvolvimento era que "os provedores da ajuda aumentem doações e subscrições de capital para programas multilaterais de ajuda ao desenvolvimento, para um mínimo de $20 \%$ do fluxo total de assistência oficial ao desenvolvimento, até 1975" (PEARSON, 1969b, p. 239). ${ }^{6}$

A premissa que respaldava essa recomendação era de que as organizações internacionais já teriam acumulado condições objetivas suficientes, uma "boa bagagem de realizações" (PEARSON, 1969b), para exercer um papel fundamental no desenvolvimento. Para a ampliação do escopo de responsabilidades das organizações internacionais além de ajustes "mecânicos", como a própria expansão de pessoal, era necessária ainda "uma revisão radical" do seu modus operandi para uma definitiva conversão da condição de fórum de atores para a condição de agentes do desenvolvimento. Essa revisão deveria levar em conta, principalmente, a política interna de cada organização vis-à-vis as relações estabelecidas entre elas. Deveria ainda deixar claro quem eram os agentes do campo (quais as fronteiras de participação), quais os capitais por eles mobilizados e quais os tipos de laços institucionais e posições de hierarquia potencialmente estabelecidos. Não só isso, essa revisão proposta deveria colocar em 
questão o senso comum até então prevalecente sobre desenvolvimento e favorecer a emergência de uma visão de mundo (mais ou menos) comum a todos os agentes em todos os países, desenvolvidos e subdesenvolvidos; visão essa a ser mediatizada pelas organizações internacionais.

Nessa perspectiva, as posições conquistadas pelas organizações internacionais desde Bretton Woods lhes possibilitaram uma capacidade crescente para produzir julgamentos objetivamente classificáveis sobre as práticas do desenvolvimento (bilateral/multilateral, ajuda oficial/não oficial, ajuda ao desenvolvimento/ajuda a outros fins, projetos específicos/projetos abrangentes, assistência técnica/assistência financeira, recursos convencionais/recursos concessionais, entre outros) e, consequentemente, para diferenciar e apreciar essas práticas a partir desses elementos de distinção. A Comissão Pearson representa, assim, um marco relevante no processo de constituição do campo, pois permitiu o exercício da atividade reflexiva dos agentes ali envolvidos ao trazer à tona esquemas perceptivos possíveis sobre como sistematizar as práticas no campo.

O interessante é que todos esses esquemas perceptivos, evidenciados no Relatório Pearson, revelam que o que estava em jogo naquele momento era a busca pela eficiência da ajuda - e não se trata de qualquer ajuda, mas de um tipo particular de ajuda oficial, multilateral e orientada para o chamado desenvolvimento. A aposta era de que a eficiência seria "simplesmente uma questão de procedimentos e técnicas", uma questão metodológica, quase mecânica. Se, por um lado, esse processo de "tecnificar" o desenvolvimento tinha como objetivo afastar influências da política internacional dos procedimentos e práticas dos organismos internacionais, por outro lado, a cooperação internacional para o desenvolvimento foi adquirindo uma lógica política própria e ganhando cada vez mais os contornos de um campo social, nos termos de Bourdieu (2007; 2008). 


\section{O Papel da ONU e do Banco Mundial na Consolidação do Campo Internacional... \\ Os Dilemas da Coordenação da Cooperação Internacional para o Desenvolvimento a partir da Comissão Pearson: A Disputa entre a ONU e o Banco Mundial}

O trabalho produzido pela Comissão Pearson pode ser lido como uma tentativa de aproximação e articulação das principais organizações internacionais comprometidas com a assistência ao desenvolvimento com vistas a estimular a reflexão sobre suas práticas vis-à-vis as demandas próprias de desenvolvimento (e não de segurança ou de comércio) colocadas pelos Estados. No momento em que representantes dessas organizações são chamados a repensar suas estratégias e seu papel na comunidade internacional, cria-se um momento único de percepção coletiva em torno de um objeto comum: a cooperação internacional para o desenvolvimento.

Se, até então, as organizações internacionais alocavam seus recursos de forma pouco reflexiva, isso é, orientadas por uma lógica que lhes era externa (ou "estruturante"), na medida em que elas passam a ser dotadas de condições objetivas de ação (capitais), elas desenvolvem as disposições que lhes possibilitam uma reflexão sobre suas práticas e sobre seu posicionamento no campo de desenvolvimento. A começar, observa-se um grande esforço para a canalização do capital econômico via mecanismos multilaterais, ainda que a ajuda bilateral prevalecesse. Também se observa que os propósitos de alocação do capital econômico multilateral foram alterados para atender a uma agenda voltada para a redução da pobreza, além dos setores tradicionalmente beneficiados, como infraestrutura.

Outro movimento interessante se deu na alocação e mobilização do capital científico, tanto em seu aspecto técnico quanto teórico. Em 
relação ao primeiro, houve uma completa reestruturação dos quadros burocráticos do Banco Mundial e da ONU para aumentar o nível de detalhamento técnico e o grau de eficiência dos projetos de desenvolvimento. Questões que antes não apareciam no campo, como o próprio ciclo de formulação de projetos, ganharam uma relevância considerável, a ponto de inaugurar toda uma tradição em gerenciamento de projetos, fortemente utilizada até os dias de hoje. Quanto ao capital científico, tem-se também um movimento de construção de conhecimento por meio do investimento em produção de dados e estudos pelos próprios especialistas do Banco Mundial ou com o seu apoio. As pesquisas do Banco Mundial mobilizavam cientistas e representantes dos governos dos Estados-membros e se destacavam pelo acesso a estudos de casos e informações pouco divulgadas sobre as políticas de desenvolvimento em vários países. Contudo, esses estudos não tinham por objetivo contestar a concepção vigente sobre desenvolvimento e careciam de uma discussão propriamente teórica, ainda restrita ao campo acadêmico.

Mas o principal desafio que emergiu neste momento estava na coordenação do campo. Com a criação de novas organizações para o desenvolvimento, a definição daqueles que seriam os agentes legítimos do campo se tornou uma questão relevante, a ponto de ser designada uma instituição responsável por sua coordenação (CAD/OCDE). Essa expansão do campo ocasionada pela inclusão de novos agentes ao mesmo tempo em que demandava um maior controle de suas fronteiras também despertava a atenção dos agentes ali envolvidos para a delimitação de suas próprias posições no campo. Esse movimento social que se inicia nos anos 1960 ganha maior intensidade após a publicação do Relatório Pearson, quando esses organismos internacionais são chamados a assumir uma posição mais comprometida e mais efetiva em suas políticas multilaterais de desenvolvimento.

Nos últimos anos, tornou-se evidente a importância da efetiva coordenação dos doadores 
O Papel da ONU e do Banco Mundial na

Consolidação do Campo Internacional...

multilaterais e bilaterais da ajuda. Tal constatação pode ajudar a assegurar que todos os doadores estejam provendo apoio consistente com os objetivos de desenvolvimento e que a ajuda técnica e financeira esteja sendo aplicada eficientemente para as necessidades prioritárias. No lado de quem recebe a ajuda, a coordenação pode facilitar um melhor planejamento e execução pelos países em desenvolvimento e, assim, possibilitar que eles utilizem a ajuda de forma mais produtiva (WORLD BANK, 1968, p. 70).

Em resposta a esse desafio, o Grupo Banco Mundial, incluindo-se a International Development Association (IDA), a International Finance Cooperation (IFC) e o BIRD, chamava para si o papel da coordenação do campo do desenvolvimento e para isso passou a investir na construção de vínculos formais e informais com os demais agentes do campo:

A experiência do Banco em coordenar a ajuda proveniente de diferentes lugares em um só país beneficiário tornou-se uma questão emergencial no verão de 1958, quando um consórcio de governos e instituições procuraram o Banco interessados em assistir a crise financeira da Índia. Desde então, o FMI, o PNUD e, quando apropriado, os bancos de desenvolvimento regionais participam dessas atividades (WORLD BANK, 1968, p. 70).

Se a maior aproximação entre as organizações do campo, por um lado, reforçou a rede social que se estabelecia entre os agentes do desenvolvimento, por outro lado intensificou a disputa simbólica entre o Banco Mundial e a ONU para liderar o campo de cooperação para o desenvolvimento. A não existência de um consenso sobre a estratégia a ser adotada de desenvolvimento intensificou a disputa entre esses dois organismos, no sentido de se adotar uma postura mais efi- 
ciente de desenvolvimento que gerasse resultados concretos na redução da pobreza.

A ONU associava essa eficiência das políticas de ajuda à própria ampliação do conceito de desenvolvimento e, consequentemente, das práticas da cooperação, para a incorporação de variáveis não econômicas na estratégia e nos instrumentos de promoção do desenvolvimento: para tanto, passou a investir fortemente na mobilização de seu capital social, convocando países-membros e organismos internacionais para a participação de conferências de alcance mundial, que tinham como objetivo disseminar sua estratégia de desenvolvimento para a comunidade internacional.

Assim, o capital social que a ONU dispunha entre países ricos e pobres e entre dezenas de agências de desenvolvimento, aliado a seu capital técnico, principalmente na capacidade de mensuração de indicadores, possibilitou-lhe uma tomada de posição mais ativa na defesa das dimensões humanas e sociais do desenvolvimento. Essa tomada de posição, porém, não era traduzida em instrumentos fortes de intervenção, pois lhe faltava capital econômico para financiar tais iniciativas.

Isso confirmava uma divisão clara: à ONU não eram confiados os instrumentos "hard" de desenvolvimento, tais como assistência financeira e formulação de políticas macroeconômicas - isso tinha que ser preservado pelas instituições de Bretton Woods com seu sistema de votos fechado e controlado pelos países industrializados ocidentais. À ONU cabia os instrumentos "soft" de cooperação, tais como ajuda no combate à fome, assistência técnica, temas relacionados a políticas sociais, crianças, mulheres e, mais recentemente, meio ambiente (SINGER, 1995, p. 380). 


\section{O Papel da ONU e do Banco Mundial na}

Consolidação do Campo Internacional...

Por isso, cabia à ONU apenas a gestão dos instrumentos soft de promoção do desenvolvimento, tais como pequenas intervenções e assistência técnica que não demandavam grandes somas de capital econômico. Os instrumentos hard de financiamento de projetos, por sua vez, estavam sob a responsabilidade das instituições de Bretton Woods - Grupo Banco Mundial e FMI.

Com isso, a divisão entre instrumentos soft e hard de desenvolvimento acabou por estabelecer uma assimetria entre as agendas de desenvolvimento adotadas pelo Banco e pela ONU, já que essa última não tinha o capital econômico necessário para colocar sua estratégia em prática. Essa assimetria entre a capacidade de implementação das políticas de desenvolvimento acabou por revelar a incapacidade da ONU em assumir o papel de coordenação da agenda internacional de desenvolvimento, pois, em alguma medida, as questões "soft" trazidas por ela estariam subordinadas às decisões "hard" do Grupo Banco Mundial (SINGER, 1995). Nessa perspectiva,

[...] o sistema "Bretton Woods" não só se tornou separado e independente, como também mais poderoso do que o sistema ONU no campo de desenvolvimento. A principal razão para isso está nos diferentes sistemas de voto e de tomada de decisão. A ONU é governada, pelo menos na área econômica, pela regra de um voto por país, enquanto o sistema "Bretton Woods" é o sistema um-dólar-um-voto. Isso garante aos países financeiramente poderosos o firme controle das instituições de Bretton Woods e isso os incentiva a concentrar seus recursos e apoio nessas instituições ao invés de direcioná-los para o sistema ONU, onde eles têm sido voto minoritário desde a independência das jovens nações (SINGER, 1995, p. 383).

Assim, o campo do desenvolvimento é marcado por forte assimetria entre os atores que o compõem. Apesar de a ONU não deter instru- 
mentos hard de intervenção, essa organização contribuirá apara ampliar aquilo que se entendia por desenvolvimento, imputando conteúdo social e humano à visão estritamente econômica. Nesse sentido, a posição tomada pela ONU de embate ao Sistema Bretton Woods contribuiu para trazer à tona a necessidade de se delimitar aquilo que estava em jogo, isto é, que desenvolvimento era esse que estava sendo buscado pelas organizações internacionais. Dois vetores pareciam possíveis: o primeiro, o vetor do desenvolvimento, tal como articulado pelo Sistema Bretton Woods e pelos países desenvolvidos, membros da OCDE; o segundo, o vetor do subdesenvolvimento, que propunha uma visão alternativa àquela do vetor desenvolvimento a partir da reestruturação do sistema econômico mundial para atender às demandas dos países subdesenvolvidos.

\section{A Consolídação do Campo de Desenvolvimento e a Nova Ordem Econômica Internacional}

Os movimentos de autodeterminação dos povos iniciado em Bandung e de reivindicações por revisão do sistema econômico mundial iniciados pela Conferência das Nações Unidas sobre Comércio e Desenvolvimento (UNCTAD, na sigla em inglês) tiveram seu auge na década de 1970 sob o apelo de uma nova ordem econômica internacional (NIEO) e se estenderam também durante a primeira metade da década de $1980 .^{7}$ O apelo pela NIEO teve como principal palco a UNCTAD e, consequentemente, produziu forte influência sobre as tomadas de posição da ONU no campo de desenvolvimento, reforçando ainda mais a separação e a assimetria entre esse sistema e as organizações de Bretton Woods. Isso porque, após praticamente uma década de tentativas frustradas de negociações entre os países do norte e os países do sul, nada havia mudado na ordem econômica mundial a favor desses últimos, intensificando o impasse norte e sul. 
O Papel da ONU e do Banco Mundial na Consolidação do Campo Internacional...

Michael Doyle (1983) analisou os desdobramentos desse impasse sobre as organizações internacionais e observou uma forte polarização entre as propostas dos países industrializados e as propostas do Terceiro Mundo no delineamento de um arranjo multilateral mais convergente a seus interesses. As propostas do sul, caso aceitas, alterariam a proporção de capital político e de participação desses países no sistema multilateral, pois demandavam (i) o aumento de voz e voto deles no Banco Mundial, (ii) a criação de uma nova organização internacional que lidasse com projetos de desenvolvimento a partir das demandas do sul e (iii) o fortalecimento da UNCTAD para que ela pudesse assumir um papel de agente de desenvolvimento e não tanto de fórum consultivo do Terceiro Mundo, como ela vinha atuando. Os países industrializados, por sua vez, não queriam alterar seu capital político nessas organizações e advogavam a favor da continuidade. Conforme Craig Murph citado por Robert Jordan (1985), o impasse se perpetuava, pois esses países acreditavam que "as instituições internacionais que trabalhavam a favor dos fracos deveriam ser mantidas fracas, ou melhor, não deveriam sequer existir. Por sua vez, aqueles que protegem os fortes deveriam continuar com sua função protetora" (JORDAN, 1985, p. 270).

Diante desse impasse, Michael Doyle (1983) observava a emergência de uma "terceira via" na busca de uma solução que atendesse aos dois lados. A Comissão Brandt, inaugurada em 1977 pelo presidente do Banco Mundial Robert McNamara, apesar de ser uma iniciativa marcadamente do norte, seria o expoente dessa "terceira via" ao buscar conciliar as propostas do sul no delineamento das diretrizes de reforma do campo de desenvolvimento. Fortemente influenciada pela teoria neofuncionalista, a Comissão Brandt era composta por economistas e outros acadêmicos que trabalhariam "independentemente" dos interesses dos Estados na formulação de uma proposta que amenizasse o impasse (MCNAMARA, 1978). A Comissão Brandt lançou luz à forte interdependência entre os países do norte e do sul em 
vários aspectos das relações internacionais e reconheceu a necessidade de se reformular as estratégias vigentes de desenvolvimento, especialmente com vistas à consideração das "necessidades humanas".

A Comissão Brandt, enquanto ressalta que há pouco a ser redistribuído aos países pobres, busca associar desenvolvimento às demandas essenciais: saúde, casa e educação. A tarefa do sul se assenta em uma estratégia "antipobreza", com prioridade para agricultura. O objetivo que os neofuncionalistas enfatizam é o de reconhecimento das necessidades e direitos dos indivíduos de modo a assegurar que todos os seres humanos tenham "uma oportunidade para viver intensamente" (STREETEN IN HAQ apud DOYLE, 1983, p. 450).

Interessante notar que a passagem acima sugere a estratégia antipobreza como uma tarefa do sul. Isso porque a Comissão Brandt não propõe uma reforma dos arranjos multilaterais vigentes, mas chama atenção para a necessidade de se repensar o ordenamento internacional a partir da estruturação da ordem doméstica. Ou seja, a proposta da "terceira via" não é a reforma do ordenamento internacional, mas a emergência de um arranjo internacional que possa constranger os países a realizar reformas domésticas para que eles (o sul) tenham condições de gerar oportunidades para todos.

Em síntese, o diálogo norte-sul clama por uma vontade política orientada para criar não somente outro arranjo interestatal como Bretton Woods (o qual, junto com o GATT, tentou constitucionalizar a ordem econômica internacional), mas para criar um arranjo transnacional que deveria versar sobre a ordem internacional e também sobre a ordem doméstica. Esse tipo de arranjo tem sido raro na história internacional (DOYLE, 1983, p. 452). 
O Papel da ONU e do Banco Mundial na Consolidação do Campo Internacional...

Assim, a terceira via, na tentativa de eliminar o impasse norte e sul, acaba por colocar o problema do desenvolvimento em novos termos: não como uma questão internacional que deveria ter uma resposta internacional, mas como uma questão internacional que deveria ser solucionada no nível doméstico a partir do apoio e das diretrizes oferecidas internacionalmente. Nessa lógica, a década dos ajustes estruturais vem reforçar essa estratégia, evidenciando a capacidade das instituições de Bretton Woods para impor sua agenda de desenvolvimento no campo da cooperação internacional. As condicionalidades macroeconômicas trazidas pelos programas de ajuste estrutural muniram o Banco Mundial de instrumentos capazes de intervir nas políticas desenvolvimentistas dos países menos desenvolvidos e, com isso, listar as prioridades que deveriam ser imediatamente atendidas por eles, no nível doméstico.

Conforme Singer (1995), por meio dos programas de ajustes estruturais, o Banco Mundial não apenas ditava uma agenda de desenvolvimento por demais ortodoxa e restrita, como também estabelecia os parâmetros de uma espécie de governança global de disciplinamento das economias menos desenvolvidas, que extrapolava as próprias fronteiras do campo, de modo que "os países deficitários eram tratados como os 'bad boys' por um FMI 'maternal' que lhes enquadrava nos 'fatos da vida'. Não só isso, o FMI e o Banco Mundial foram criados para mudar esses fatos" (SINGER, 1995, p. 386). Nessa lógica, aqueles que não adotassem o sistema econômico liberal, os "bad boys", estariam excluídos dos fluxos da ajuda internacional. Cabe considerar que essa agenda de reformas econômicas foi adotada não só pelos organismos internacionais com sede em Washington (Banco Mundial, FMI, USAID e BID), mas também pelas agências bilaterais até então fortemente comprometidas com a temática da pobreza:

Isso também influenciou a ajuda internacional proveniente dos países nórdicos e de outros do- 
adores que outrora mantinham a redução da pobreza como o maior objetivo. Os programas de ajuste estrutural se tornam dominantes na cooperação internacional para o desenvolvimento de modo que quase todos os doadores bilaterais aceitaram trabalhar dentro desse marco (MARTINUSSEN; PEDERSEN, 2003, p. 27).

A década de 1980 revela, assim, uma tomada de posição de liderança do Banco Mundial no campo do desenvolvimento a partir de uma tentativa de conciliar as demandas do norte e do sul. Essa liderança, porém, estava longe de ser baseada em uma autoridade consentida pelos demais agentes, pois, como vimos, a ONU intensificou sua tomada de posição de embate às políticas do Banco Mundial, e, em meados dos anos 1980, assumiu uma posição explícita de dissidência: "nos anos 1980, as Nações Unidas adotaram o papel de uma dissidência construtiva. Em 1985, a UNICEF começou a promover a necessidade de um 'ajuste com face humana'. Em paralelo, a ECA clamava pela promoção de um programa de ajuste estrutural alternativo para a África" (JOLLY et al., 2005, p. 11).

\section{Considerações Finais}

A construção de um projeto de cooperação internacional para o desenvolvimento no sistema internacional não foi um empreendimento alcançado de imediato. Esse projeto demandou tanto a constituição de agentes, dotados de capacidades objetivas de ação, como também disputas práticas e simbólicas pela definição de uma gramática própria de desenvolvimento de uma doxa que informaria àqueles agentes o sentido do jogo. Ou seja, a agência e a estrutura do campo estavam sendo construídas (e reconhecidas como tal) na e pela performance das práticas mais rotineiras das organizações internacionais, tais como: a definição das linhas temáticas de financiamento de projetos, a criação de uma estrutura burocrática altamente especializada 
ou a publicação de estudos e informativos sobre os problemas do desenvolvimento.

Nesse sentido, o Banco Mundial, por ser o agente mais poderoso (que detinha os instrumentos hard) e por ser muitas vezes pioneiro na institucionalização de certas práticas, exerceu um papel fundamental na constituição do campo ao apontar e legitimar quais eram os capitais válidos, bem como o seu modus operandi - que ficou claramente expresso no Relatório Pearson. Contudo, a despeito da estabilização desse modus operandi, ainda havia uma disputa em torno da agenda de desenvolvimento a ser promovida pelos organismos internacionais, tendo em vista a existência de um projeto alternativo àquele promovido pelo Banco Mundial. Esse projeto - ou essa agenda alternativa -, como vimos, visava uma solução internacional para os problemas domésticos do subdesenvolvimento por meio da alteração dos padrões vigentes da relação norte e sul, o que, por sua vez, ameaçaria a própria estabilidade das práticas já instituídas.

A ONU foi a organização mais expressiva do campo a manifestar essa agenda alternativa, por ser mais aberta às demandas do Terceiro Mundo, e propôs uma concepção de desenvolvimento "mais humana", que levasse em conta os problemas fundamentais da pobreza. A resposta encontrada pelo Banco Mundial foi justamente a incorporação do discurso da pobreza em sua rotina, moldando esse discurso à sua maneira, conforme sua cesta de capitais econômicos, científicos e, sobretudo, morais. Com essa tomada de posição, o Banco trazia para o seu entorno as reivindicações do Terceiro Mundo e buscava oferecer soluções a elas a partir de sua experiência prática.

O domínio do Banco em ditar as regras do jogo e impor sua doxa de desenvolvimento ficou claro com os ajustes estruturais, quando outras organizações internacionais também passaram a adotar o modelo proposto por ele. Nesse momento, o projeto de uma nova ordem econômica internacional começa a perder fôlego diante da distensão 
do conflito leste e oeste. Além disso, ao colocar o ajuste estrutural na agenda do desenvolvimento, o Banco Mundial conseguiu alterar os termos do problema: desenvolvimento continuava como uma questão internacional, cuja solução para promovê-lo não dependia mais de uma reforma do sistema econômico internacional, mas de reformas domésticas para o ajuste econômico dos Estados. Ou seja, ao colocar a promoção do desenvolvimento como uma questão de medidas macroeconômicas a serem adotadas pelos Estados em um âmbito doméstico, esvaziava-se a reivindicação do Terceiro Mundo por redistribuição no sistema de Estados. Não só isso, a regra era tirar o Estado de cena e deixar que a eficiência do mercado se encarregasse do desenvolvimento.

Ainda que nossa análise não tenha avançado para além dos anos 1980, as observações coletadas até aqui sugerem que o fim da Guerra Fria consagrará o campo do desenvolvimento tal como colocado pelo Banco Mundial nesse período, pois o fim da União Soviética e, consequentemente, do projeto socialista esvaziou ainda mais a reivindicação do sul por uma nova ordem econômica internacional. Esse esvaziamento acabou por minar a doxa alternativa ao desenvolvimento, consagrando a batalha já ganha pelo Banco Mundial. Consequentemente, os agentes do desenvolvimento passaram a ser aqueles que orientam suas práticas em consistência à estratégia adotada pelo Banco Mundial.

Até mesmo a ONU se viu constrangida a tirar de pauta a temática da redistribuição, pois essa demanda perde seu sentido no pós-Guerra Fria. Em contrapartida, novas temáticas trazem o "sopro de vida ao desenvolvimento" necessário para legitimar esse projeto e reanimar aquelas organizações internacionais então insatisfeitas com o Sistema Bretton Woods. Dentre essas temáticas, destacamos sustentabilidade, desenvolvimento humano e boa governança; todas relacionadas diretamente à capacidade dos governos domésticos em criar espaços e instrumentos próprios de promoção do desenvolvimento. Nessa perspectiva, a década das conferências organizadas pela ONU 


\section{O Papel da ONU e do Banco Mundial na}

Consolidação do Campo Internacional...

durante os anos 1990 pode ser interpretada como a tentativa da ONU de imputar sua agenda social ao modelo de desenvolvimento que sai vitorioso no pós-Guerra Fria: "muitas das contribuições pioneiras da ONU são tão aceitas nos dias de hoje que é difícil relembrar quão extensas foram as controvérsias e as paixões que marcaram sua aceitação e adoção" (JOLLY, 2005, p. 15).

Essa agenda, por sua vez, será realizada segundo o modus operandi das práticas de desenvolvimento inaugurado pelo Banco Mundial nas sombras de Bretton Woods e atualizado pela Comissão Pearson. É esse modus operandi, portanto, que permeará a estrutura do campo de desenvolvimento que será vislumbrada no pós-Guerra Fria.

Com isso, podemos concluir que o Banco Mundial não só conseguiu delimitar os termos do problema, demarcando as fronteiras do campo, como também impediu que outro campo emergisse no entorno da ONU, orientado pela doxa alternativa do subdesenvolvimento. Assim, os anos 1980 já anunciavam a vitória do vetor desenvolvimento e, doravante, os "subdesenvolvidos" ou "menos desenvolvidos" seriam promovidos à condição de "em desenvolvimento".

\section{Notas}

1. A definição preliminar de grande parte dos elementos de estruturação desse arranjo multilateral que, mais tarde, tornar-se-ia o principal financiador do desenvolvimento das nações mais pobres esteve concentrada nas mãos de representantes dos 44 países reunidos na Conferência Monetária e Financeira Internacional das Nações Unidas, realizada na cidade de Bretton Woods, em 1944.

2. Esta e as demais citações de originais em língua estrangeira foram livremente traduzidas por nós para este artigo.

3. Como uma forma de agradecimento, o Banco Mundial chegou a oferecer o relatório para subsidiar o trabalho das Nações Unidas na preparação da segunda década do desenvolvimento. "A Comissão muito agradece a valiosa assistência 
e cooperação que prestaram os organismos internacionais, governos e particulares. Confia especialmente que este relatório sirva de ajuda para os debates que estão em curso nas Nações Unidas a fim de preparar a Segunda Década para o Desenvolvimento" (PEARSON, 1969a, p. 10).

4. Em 1967, essa modalidade de ajuda foi responsável por quase $90 \%$ da assistência oficial ao desenvolvimento. (PEARSON, 1969b, p. 233).

5. Na América Latina, a insatisfação com as instituições de Bretton Woods e Nações Unidas já podia ser observada desde os anos 1950, quando o então secretário da Comissão Econômica para América Latina, Raúl Prebisch, coordenou a elaboração do primeiro "draft" do Banco Interamericano de Desenvolvimento que teria como objetivo promover o desenvolvimento econômico por meio do financiamento não só a projetos produtivos, no sentido tradicional adotado pelo Banco Mundial, mas também a projetos de infraestrutura mais amplos, como estradas, saneamento, agricultura, abastecimento de água que atendessem diretamente às demandas locais (DELL, 1972). Após intensas pressões, os Estados Unidos aceitaram a concretização desse projeto em 1960, quando o BID foi estabelecido oficialmente.

6. Esse cálculo se baseou na expectativa de que, caso essa meta fosse alcançada, a ajuda multilateral passaria a responder por um terço de toda a ajuda oficial para o desenvolvimento, ficando os dois terços restantes para a ajuda bilateral.

7. A proposta por uma nova ordem econômica internacional foi formalmente apresentada pelos países do Terceiro Mundo e adotada pelas Nações Unidas em 1974, na 6 a Seção Especial da Assembleia Geral das Nações Unidas, com a aprovação da Resolução 3201 intitulada Declaração para o Estabelecimento de uma Nova Ordem Econômica Internacional e da Carta de Direitos e Deveres Econômicos dos Estados. Essa resolução foi aprovada unanimemente pelos países menos desenvolvidos, inclusive países socialistas, e por apenas oito países-membros da OCDE. Os demais países industrializados votaram contra a resolução ou se abstiveram (JACOBSON et al., 1983).

\section{Referências Bibliográficas}

BOURDIEU, Pierre. A economia das trocas simbólicas. 6. ed. São Paulo: Perspectiva, 2007. 


\section{O Papel da ONU e do Banco Mundial na Consolidação do Campo Internacional...}

A distinção: crítica social do julgamento. Tradução de Daniela Kern e Guilherme Teixeira. Porto Alegre: Editora Zouk, 2008.

DELL, Sidney. Inter-American Development Bank: Study in Development Financing. Santa Bárbara: Praeger Publishers, 1972.

DOYLE, Michael. Stalemate in the North-South Debate. Strategies and the New International Economic. World Politics, v. 35, n. 3, 1983.

JACOBSON, Harold K.; DUSAN, Sidjanski; JEFFREY, Rodamar; HOUGASSIAN, Rudovich Alice. Revolutionaries or Bargainers? Negotiators for a New International Economic Order. World Politics, v. 35, 1983.

JOLLY, R.; EMMERIJ, L.; WEISS, T. The Power of UN Ideas. Lessons from the 60 Years. In: United Nations Intellectual History Project Series. Nova York: [s.n.], 2005.

JORDAN, Robert. Review The Emergence of the NIEO Ideology by Craig Murphy. The American Political Science Review, v. 79, 1985.

MCNAMARA, Robert. Discurso proferido no Diretório de Governadores do Banco Mundial. Washington, D.C., 1978. In: WORLD BANK. Address to the Board of Governors Robert s. McNamara President. Washington, D.C., 25 set. 1978.

MARTINUSSEN, John; PEDERSEN, Poul. Aid: Understanding International Development Cooperation. Londres: Zed Books, 2003.

OCDE - Organização para a Cooperação e Desenvolvimento Econômico. Definição de OAD. [s.d.]. Disponível em: <http://www.oecd.org/glossary>. Acesso em: 13 dez. 2009.

PEARSON, Lester (Org.). Sócios no progresso: relatório da Comissão de Desenvolvimento Internacional. [s.l.]: APEC (versão traduzida), 1969a.

(Org.). El desarrollo: empresa comun. Informe de la Comisión de Desarrollo Internacional. Madri: Tecnos, 1969b.

SINGER, Hans W. Half a Century of Economic and Social Development Policies of the UN and Bretton Woods Institutions. The Pakistan Development Review, Winter, p. 375-392, 1995.

WORLD BANK. Policies and Operations. Washington, D.C: World Bank, 1968. 


\section{Resumo}

\section{O Papel da ONU e do Banco Mundial na Consolidação do Campo Internacional de Desenvolvimento}

O artigo tem por objetivo resgatar o processo histórico de construção do modus operandi das práticas de desenvolvimento, destacando o papel das organizações internacionais nesse processo e como elas mobilizavam seus recursos tangíveis e intangíveis para a conformação de uma agenda legítima de intervenção social. A análise terá como foco as dinâmicas políticas que sucederam a Comissão Pearson, conferência internacional realizada em 1969, que teve como objetivo repensar e propor diretrizes internacionais para o desenvolvimento. O ponto crítico deste momento será o reconhecimento, por parte do Banco Mundial e da ONU, de que a cooperação internacional para o desenvolvimento mobilizava diferentes projetos de coordenação societária que tinham como pano de fundo o problema da desigualdade internacional. A partir da análise dos documentos e discursos da época, é possível perceber que, embora a ONU e o Banco Mundial compartilhassem a percepção de que a ajuda internacional ainda teria um papel a cumprir, esses organismos ofereciam agendas distintas para solucionar o problema do subdesenvolvimento. Com isso, buscar-se-á identificar o projeto que sai vitorioso desse embate e nos fornece elementos para a compreensão da sobrevivência e ampliação da agenda de desenvolvimento no pós-Guerra Fria.

Palavras-chave: Cooperação Internacional para o Desenvolvimento Banco Mundial - ONU - Desigualdade Internacional - Instituições Internacionais

\section{Abstract \\ The Role of UN and World Bank in the Consolidation of the Field of International Development}

This paper draws on the historical process of construction of the modus operandis of development practices in order to understand the role of international organizations in mobilizing the resources necessary for the 


\section{O Papel da ONU e do Banco Mundial na}

Consolidação do Campo Internacional...

consolidation of the field of international cooperation. The analysis focuses on the aftermath of the Pearson Commission (1969), which goal was to make recommendations for future operation of international development practices. The main finding is that although both World Bank and UN shared the understanding that international aid was crucial to fight global inequality, they offered different agendas to solve the problem of underdevelopment. The paper concludes that the victorious agenda was the one supported by the World Bank, influencing the development cooperation dynamics afterwards.

Keywords: International Development Cooperation - World Bank - UN International Inequality and Redistribution - International Organizations 